\title{
DIMENSÕES POLÍTICO-COMUNICACIONAIS DOS VIDEOGAMES: UMA ANÁLISE DOS ELEMENTOS PRESENTES NO DISCURSO E NA JOGABILIDADE DE UNDERTALE
}

\section{ARTIGO ORIGINAL}

RIMI, Tulio Girelli ${ }^{1}$

COSTA, Rogério da ${ }^{2}$

RIMI, Tulio Girelli. COSTA, Rogério da. Dimensões político-comunicacionais dos videogames: uma análise dos elementos presentes no discurso e na jogabilidade de UNDERTALE. Revista Científica Multidisciplinar Núcleo do Conhecimento. Ano 04, Ed. 11, Vol. 01, pp. 05-17. Novembro de 2019. ISSN: 24480959, Link de

acesso: https://www.nucleodoconhecimento.com.br/comunicacao/dimensoespolitico-comunicacionais

\section{RESUMO}

Este artigo tem como objetivo analisar interpretações de teorias políticocomunicacionais nas estruturas de videogames, tendo como caso a ser analisado o videogame UNDERTALE. A discussão se inicia apresentando o jogo escolhido para que assim se possa, em meio à história do videogame, introduzir os conceitos de Gilbert Simondon (sobre o processo de individuação), Gregory Bateson (acerca do duplo vínculo e formas diferentes de aprendizagem) e Giorgio Agamben (um debate

1 Mestrado em andamento em Comunicação e Semiótica. Graduação em Comunicação Social - Publicidade e Propaganda.

2 Doutorado em História da Filosofia; Mestrado em Filosofia; Especialização em História das Ciências; Especialização em Filosofia Leibniz e o Barroco; Especialização em Filosofia; Graduação em Engenharia de Sistemas e Computação. 
sobre o estado de exceção). Por fim, é estabelecida uma relação entre os conceitos apresentados com a narrativa e as mecânicas de UNDERTALE, e são apresentados novos questionamentos para futuros estudos.

Palavras-chave: individuação, duplo vínculo, estado de exceção, videogames, UNDERTALE.

\section{INTRODUÇÃO: APRESENTANDO UNDERTALE}

Este trabalho tratará de relacionar o caso selecionado do videogame UNDERTALE com os conceitos de duplo vínculo, estado de exceção e individuação. O jogo será analisado sob a ótica da tomada de decisão, observando as possibilidades de repercussão tanto teóricas quanto práticas sobre todo o processo de escolha envolvido, podendo, dessa forma, contribuir para uma análise que compreenda tanto as mecânicas do videogame quanto sua narrativa. Neste primeiro momento, será introduzido o caso a ser analisado. UNDERTALE (2015) é um jogo de RPG (roleplaying game) no qual o jogador "não precisa matar todo mundo". Cada luta poderá ser vencida inofensivamente, bastando para isso que os jogadores consigam "dançar com lesmas, fazer carinho em um cachorro, contar seus segredos para um cavaleiro. Ou (...) ignorar isso e destruir todos os seus inimigos". ${ }^{[3]}$ Sua história se inicia quando um humano, ao escalar o monte Ebott, tropeça e cai no mundo dos monstros, localizado abaixo da superfície da Terra, dando início à sua jornada para voltar para casa. Um dos pontos principais do jogo é o combate, marcado por duas opções: Fight ou Mercy (lutar ou poupar). Dessa forma, o jogo possui duas rotas principais: a pacifista e a genocida; e também a rota neutra, caso o jogador se encontre no meio desses dois extremos.

Por essa especificidade, grande parte da estrutura narrativa de UNDERTALE flerta com as escolhas que os jogadores farão no decorrer da história, apresentando personagens com várias inclinações éticas e morais: aqueles que acreditam em resoluções pacíficas e outros que, se aproveitando do fato de que a maioria dos monstros neste mundo tentará atacar, insistem que o mundo é regido pela lógica de 
"matar ou morrer", atiçando assim a agressividade e a desconfiança no jogador. Adicionalmente, os resultados das escolhas feitas não são imediatos, no sentido de que nem sempre o jogador pode matar ou poupar imediatamente um inimigo, pois há monstros mais difíceis de serem mortos ou poupados. A maior parte das escolhas feitas no jogo acarreta suas devidas consequências, geralmente mostradas por mudanças nos diálogos com os personagens, sendo eles aliados ou inimigos. Além disso, um grande ponto de UNDERTALE, que o diferencia de outros jogos que se utilizam de mecânicas similares, está na questão da temporalidade. Por exemplo: se um jogador acidentalmente matar um personagem e decidir por reiniciar o jogo para corrigir esse "erro", há uma grande probabilidade de que, apesar disso, algum diálogo mudará; como se o jogo remetesse às características do mundo "real", ou seja, o fato de que não é possível voltar atrás de determinadas escolhas na vida.

\section{O PROCESSO DE INDIVIDUAÇÃO}

Para iniciar essa análise, apresenta-se aqui o conceito de individuação - mais especificamente o pré-individual e o individual - de Gilbert Simondon, lido por Gilles Deleuze. A filosofia grega sempre entendeu o indivíduo como algo acabado, realizado. Daí o conceito de substância em Aristóteles. Mesmo entendendo que o indivíduo está na temporalidade, suas mudanças seriam atribuídas ao que lhe é acidental, sua essência permanecendo sempre a mesma. A substância não muda, e o princípio de individuação buscaria explicar como ela se individua. A diferença nesse raciocínio, introduzida por Simondon, é que ele criticou essa ideia de um princípio já estabelecido de individuação, afirmando que ele, por si só, apenas caracteriza um ser que já é individuado. Logo, tal conceito de individuação é apresentado como algo que contempla todo o ser e que é o primeiro momento desse ser fora do conceito; e para Simondon, isso caracteriza um erro correlativo ao precedente. Para ele, a individuação deve ser contemporânea ao indivíduo, não podendo ser entendida como algo que o antecede, ou que determina um momento situável e estável na composição do ser, o momento em que ele passa de uma pré-individualidade para a individualidade (DELEUZE, 2003). Ao contrário, a pré-individualidade seria o "metaestável", algo "provido de singularidades que correspondem à existência e à repartição dos 
potenciais" (DELEUZE, 2003, p. 121) e, dessa forma, carregando consigo a inúmera quantidade de singularidades possíveis de serem assimiladas durante o processo de individuação, que não se encerra. $O$ indivíduo, de fato, é teatro de individuação permanente. Esse processo, então, diz respeito aos momentos nos quais são engendradas "soluções" para os "problemas" das diversas possibilidades do préindividual, criando assim fases de desenvolvimento do próprio ser (DELEUZE, 2003).

É possível perceber uma correspondência estrutural de UNDERTALE com o processo de individuação acima citado. Os jogadores, ao iniciarem sua jornada no jogo, possuem um universo de possibilidades de batalhas e situações para serem vivenciadas, antes de tomarem qualquer decisão. Por essa característica, esse universo de possibilidades se assemelha ao universo de singularidades correspondente ao nível do pré-individual. Todos os jogadores, independentemente de qual rota seguiram no decorrer do jogo, possuem todas essas possibilidades de jornadas à sua disposição no início. Se seguirmos essa lógica, consequentemente o ato da escolha - entre Fight ou Mercy, lutar contra o inimigo ou arriscar um desfecho pacífico da batalha - diz respeito ao processo de individuação em si, no qual o indivíduo, baseado na comunicação com as múltiplas singularidades encontradas no pré-individual, cria fases de desenvolvimento do seu ser, assimilando-as em sua individualidade.

Porém, UNDERTALE fornece mudanças de caminho em vários momentos de sua narrativa. Portanto, de que forma o processo de individuação é afetado por isso? Pode-se observar a situação de início do jogo. A personagem Flowey, antagonista principal, é apresentada de uma forma inocente, tomando a aparência de uma flor, mas é o primeiro personagem na narrativa a infligir algum tipo de dor no protagonista. Os diálogos de Flowey (principalmente no início e no final do jogo) são marcados por sua crença forte de que a lógica de "matar ou morrer" é a única solução para o mundo dos monstros atualmente. Em seguida, o personagem encontra Toriel que, antagonicamente, se torna uma figura materna para o personagem principal, fornecendo abrigo e segurança a quem estava correndo risco poucos segundos antes. É Toriel quem ensina que sempre há um jeito pacífico de resolver qualquer confronto, 
pouco tempo depois de outra personagem deixar claro que todos no mundo dos monstros querem o seu mal. Dúvida e ambivalência entre "matar ou morrer", lutar ou piedade e, essencialmente, paz e guerra, remetem ao conceito de "duplo vínculo" desenvolvido por Gregory Bateson, bem como à aprendizagem pela diferença e não por forças ou impactos - conceitos que serão explicitados a seguir.

\section{O DUPLO VÍNCULO E OS PROCESSOS DE APRENDIZAGEM}

A teoria do duplo vínculo, descrita pela primeira vez por Gregory Bateson, remete a uma situação de dilema ou ambiguidade na comunicação, na qual um indivíduo é exposto a duas ou mais mensagens conflitantes, em que uma se opõe à outra, ou porque os emissores possuem poderes diferentes (BATESON, 2006). Bateson chegou a essa teoria por meio de estudos de casos de esquizofrenia. Em meio a esses estudos, ele comenta seis características presentes em uma situação de duplo vínculo: duas ou mais pessoas; uma experiência que ocorre repetidamente; uma injunção negativa primária; uma injunção negativa secundária que entre em conflito com a injunção primária (aqui justificando a contradição); uma injunção negativa terciária que impeça que o sujeito saia da situação e, por último, quando o sujeito aprendeu a perceber seu universo pelo duplo vínculo, todo esse conjunto de elementos não será mais necessário (BATESON, 1978).

Complementarmente, o autor estuda implicações das situações de duplo vínculo na aprendizagem, e se pergunta: "o que acontece quando você desorganiza o 'aprender a aprender' (...)? A resposta a esta pergunta teria sido, naturalmente, a teoria do duplo vínculo'." (BATESON, 2006, p. 264). Bateson entende que seria preciso um novo modelo de aprendizagem para se compreender a teoria do duplo vínculo. Ele percebe, também, a importância da interação no processo de aprendizagem, criticando o modelo repetido e unidirecional pelo qual aprendemos e apresentando a ideia de que passos mais aleatórios na aprendizagem têm surtido mais efeito nesse processo. Assim, o ato de desorganizar o "aprender a aprender", ao qual o autor se refere, assemelha-se ao processo de Cismogênese, que significa uma mudança de direção em um sistema de aprendizagem (BATESON, 2006). 
Baseando-se no que foi visto até agora, é possível entender o real significado do seguinte trecho: "é característico da mente e dos processos mentais o fato de que, em muitos dos passos que constituem os circuitos da mente, os eventos sejam causados, não por forças ou impactos, mas por diferenças" (BATESON, 2006, p. 266). verdadeiro aprendizado ocorre, portanto, quando somos confrontados com o que é novo e/ou diferente, desse modo atualizando nossas perspectivas sobre diversos aspectos do mundo. Podemos observar algo semelhante a isso quando Bateson comenta que "o que eu vejo quando olho para você é, na verdade, a imagem que eu tenho de você ou você vê a imagem que você tem de mim. Estas imagens parecemnos projetadas no mundo exterior, mas estão muito longe daquilo que dizemos "vemos" (BATESON, 2006, p. 272). Isso ocorre, de certa forma, porque a epistemologia inconsciente (ou seja, como utilizar nossos sentidos) é considerada uma espécie de conhecimento essencialmente oculta, a fim de manter a realidade do que chamamos de "si mesmo"; tanto que, quando confrontados pelas diferenças na aprendizagem da ordem do duplo vínculo, nossas percepções do "si mesmo" são abaladas (BATESON, 2006).

Enfim, é colocado o seguinte questionamento: o que motiva alguns indivíduos a voluntariamente se colocarem em situações de duplo vínculo dolorosas? Como, por exemplo, um monge ficar sentado horas a fio em posição de lótus, com as pernas paralisadas? Bateson imagina que, nesses casos, esses indivíduos acreditem que, dessa aventura disciplinar, virão recompensas hedonistas ou espirituais, que ele enxerga como vícios positivos aos sofrimentos de enfrentar tais duplos vínculos e, portanto, obstáculos a serem vencidos (BATESON, 2006).

Tal situação pode se assemelhar à escolha dos jogadores de UNDERTALE de realizar a rota pacifista - uma rota à primeira vista mais difícil, pois você não se fortalece a cada encontro, mas mais gratificante, por um lado, pois dura o dobro da rota genocida, dando ao jogador mais tempo de entretenimento com o jogo - caracterizando assim um vício positivo. A presença do duplo vínculo, nesse caso, coloca em questão a própria individuação do jogador, uma vez que, em determinadas situações encontradas em UNDERTALE, é possível que ele se surpreenda com suas próprias 
escolhas, confrontando seus mais profundos valores e ideais sobre o que é a "coisa certa" a ser feita. Neste momento, as palavras de Bateson sobre a diferença entre as imagens que temos do outro e aquilo que, de fato, vemos, pode ser aplicada no encontro do jogador com sua própria imagem, refletida no personagem principal de UNDERTALE, oferecendo uma chance de olhar para si mesmo de um jeito que, talvez, nunca tivesse se olhado. Dessa forma, as recompensas positivas de se fazer uma rota pacifista em UNDERTALE ocorrem diretamente no jogador, não no protagonista.

Se voltarmos para a história de UNDERTALE, podemos verificar um duplo vínculo existente na relação com Toriel. No início do jogo, ela abriga o protagonista em sua casa, oferecendo um ambiente aconchegante e longe dos perigos do mundo dos monstros. Apesar disso, o jogador não conseguirá prosseguir nesta situação. Sendo assim, o protagonista deverá sair da casa de Toriel. Ao perceber isso, Toriel fará de tudo para manter o protagonista lá dentro até que, sem opções restantes, ela entrará em uma batalha com ele para saber se, de fato, o protagonista está preparado para o mundo. O jogador então se encontra na possibilidade de matar Toriel ou poupá-la. Caso o jogador a mate, ele pode entrar no conflito de ter matado talvez a única personagem no jogo que o teria ajudado, já que Flowey anteriormente disse que aquele mundo era "matar ou morrer". E caso ele a poupe, ela pedirá para ele nunca mais vê-la ou voltar em sua casa, em seguida abraçando o protagonista como uma despedida. Desse modo, o jogador se encontra em uma posição que gerará insatisfação em qualquer instância - característica principal do duplo vínculo - pois, matando-a ou poupando-a, ele entenderá que desperdiçou uma chance de ter uma aliada neste mundo. Olhando para a situação apresentada, vemos que ela preenche os critérios para um duplo vínculo comentados por Bateson, possuindo: duas pessoas envolvidas (o protagonista e a Toriel); uma experiência repetida (a lógica de lutar ou poupar se repetirá durante o jogo inteiro) e injunções de ordem primária (matar Toriel significa destruir a única possível aliada neste mundo), secundária (poupar Toriel e ir embora significa abandonar essa única aliada) e terciária (o jogo não prosseguirá se continuar na casa de Toriel) - configurando assim, estruturalmente, uma situação de duplo vínculo, fazendo com que o jogador enxergue UNDERTALE sob essa lógica. 
Adicionalmente, Bateson comenta que um dos comportamentos de alguém que vivencia um relacionamento em duplo vínculo é de assumir que, por trás de cada declaração, existe algum tipo de sentido oculto que será prejudicial ao seu bem estar, desencadeando, dessa forma, um comportamento desafiador e suspeito (BATESON, 1978). Podemos enxergar tal ocorrência em UNDERTALE baseando-se no exemplo apresentado, no sentido de que o jogador, ainda confuso sobre sua escolha com relação à Toriel, pode agravar a sua suspeita dos outros monstros serem seus inimigos ou desafiar suas próprias convicções sobre lutar ou poupar.

Outra possibilidade de encontrar o duplo vínculo em UNDERTALE estaria relacionada ao que Bateson diz sobre os processos de aprendizagem se darem, preferencialmente, quando somos confrontados pela diferença ao invés de forças e impactos. A própria existência de uma opção de não matar o outro configura uma diferença com o padrão dos RPGs tradicionais, no qual o jogador deve eliminar os inimigos que atrapalham o seu caminho para ficar mais forte (pode-se observar isso em diversos videogames pertencentes a séries famosas, como The Legend of Zelda, Final Fantasy, Marios Bros., Pokémon, entre outros). Dado o sucesso dessas séries, é de se imaginar que seria um grande desafio "desaprender" as regras que estabeleceram, e é este desafio que os jogadores pacifistas de UNDERTALE enfrentam. Outro desafio para eles estaria em aprender como se comportar frente às suas decisões pacifistas tanto dentro quanto fora do jogo - que pode implicar, inclusive, em aprender um novo olhar para o que significa jogar um jogo de RPG. Complementarmente, a agressividade e a decisão de matar um adversário remetem, de certa forma, às forças e impactos, pois matar seus inimigos não necessariamente significa entrar em um processo de aprendizagem. Esse seria o mesmo tipo de comportamento que se tem na maioria dos outros RPGs. Portanto, continuar com esse comportamento, nessa situação, não acresce os valores que UNDERTALE deseja despertar. Além disso, em uma rota genocida, não existem tantos diálogos e a quantidade de inimigos diminui conforme o jogador fica mais forte, como se os monstros conversassem entre si e coletivamente decidissem fugir ou se afastar do 
personagem genocida; configurando assim uma rota sem muitos encontros (portanto sem muitas diferenças) e, consequentemente, um caminho mais solitário.

Caso o jogador opte pela rota neutra ou pacifista, ao final do jogo ele aprenderá a verdadeira história dos monstros que vivem no subterrâneo. Após uma grande guerra contra o mundo dos humanos, os monstros ficaram presos por uma barreira mágica no subterrâneo, que só poderá ser quebrada com o poder de sete almas humanas, ou apenas atravessada usando o poder de duas almas: uma de um humano e outra de um monstro. No entanto, o personagem principal não foi o único humano a adentrar o mundo subterrâneo recentemente: outro humano esteve na mesma situação e foi abrigado pela família real - na qual Toriel era a rainha. A família real, composta por Toriel, Asgore (o rei) e Asriel (seu filho) tratou o humano como família, até o dia em que o humano faleceu, fazendo com que Asriel, despedaçado pela sua dor, absorvesse a alma do humano e, dessa forma, conseguisse levá-lo de volta a seu mundo, atravessando a barreira. Os outros humanos, vendo a cena, assumiram que Asriel tivesse matado o humano, e o atacaram fortemente até destruí-lo. Tendo sofrido duas perdas na sua família em uma só noite, Asgore declarou que todos os humanos que caíssem no mundo subterrâneo deveriam morrer, protegendo sua família de mais dor e acumulando almas humanas suficientes para quebrar a barreira.

Esse estado em que a monarquia do jogo se encontra remete muito à situação do estado de exceção, trabalhada por Agamben, próximo conceito a ser discutido neste trabalho.

\section{DETERMINANDO O CONCEITO DE ESTADO DE EXCEÇÃO}

Giorgio Agamben define estado de exceção como algo semelhante a uma "terra de ninguém", localizada entre o direito público e o fato político, entre a ordem jurídica e a própria vida, entre o direito e o vivente. Muitas vezes, é utilizado para manter a ordem nacional em tempos de crise política, nos quais as ordens jurídicas (e, consequentemente, algumas liberdades individuais que vão de encontro ao sistema político vigente) são suspensas, a fim de manter a segurança do Estado. Os regimes 
totalitários vividos no século XX se utilizaram dessa prática, por exemplo. Por isso, Agamben enxerga que o totalitarismo moderno poderia ser definido como a instauração de uma guerra civil cujos objetivos não se limitam apenas à eliminação dos adversários, mas também de categorias inteiras de cidadãos - tudo em nome da proteção do Estado (AGAMBEN, 2007).

Como mais exemplos de situações em que o estado de exceção marca sua presença constitucional durante a história, temos o governo de Charles de Gaulle, que assumiu a presidência da França em 1959, no qual possuía, em sua constituição, um artigo que especificava que:

O presidente da República tomará as medidas necessárias quando as instituições da República, a independência da nação, a integridade de seu território ou a execução de seus compromissos internacionais estiverem ameaçados de modo grave e imediato e o funcionamento regular dos poderes públicos constitucionais estiver interrompido (AGAMBEN, 2007, p. 27).

Este último trecho denota claramente as situações extremas que favorecem o estabelecimento de um estado de exceção, bem como o poder que será entregue ao então denominado presidente da República, tudo pela finalidade de manter o controle da nação. Outro exemplo a ser analisado seria o de George W. Bush, presidente dos Estados Unidos, que, após os atentados de 11 de setembro de 2001, se autodenominou como "comandante em chefe do exército" ("Commander in chief of the army"). Dessa forma, Bush estaria, então, tornando uma medida do estado de exceção em uma regra; transferindo o poder do Congresso americano de declarar guerra para o próprio presidente (AGAMBEN, 2007).

Desse modo, Agamben nota a presença de estados de emergência permanentes criados voluntariamente nos Estados contemporâneos - inclusive em regimes democráticos:

Diante do incessante avanço do que foi definido como uma "guerra civil mundial", o estado de exceção tende cada vez mais a se apresentar como o paradigma de governo dominante na política contemporânea. Esse deslocamento de uma medida provisória e excepcional para uma

Disponível em: https://www.nucleodoconhecimento.com.br/comunicacao/dimensoes-politico- 
técnica de governo ameaça transformar radicalmente - e, de fato, já transformou de modo muito perceptível - a estrutura e o sentido da distinção tradicional entre os diversos tipos de constituição. $O$ estado de exceção apresenta-se, nessa perspectiva, como um patamar de indeterminação entre democracia e absolutismo (AGAMBEN, 2007, p. 13).

Portanto, ao tornar "regra" a existência do estado de exceção, nota-se que, ao se apresentar como uma técnica de governo, muito mais do que uma medida emergencial, ele revela a sua natureza oculta de paradigma constitutivo da ordem jurídica; principalmente ao delimitar leis que contradizem a própria hierarquia existente entre lei e regulamento - base das constituições democráticas - incumbindo ao governo um poder que deveria ser exclusivo do Parlamento. Assim, o estado de exceção acaba por tornar-se uma forma de incluir na ordem jurídica a própria exceção, criando dessa forma uma zona de indiferenciação na qual os limites entre fato e direito se tornam incertos. (AGAMBEN, 2007)

Há que se pensar até que ponto a própria organização das ordens jurídicas favorece a criação de estados de exceção contemporâneos. Agamben faz uma analogia interessante dizendo que, da mesma forma que a lei pode ter lacunas, mas o direito não as admite, o estado de exceção pode ser visto como um tipo de lacuna no direito público, sobre a qual o poder executivo é forçado a intervir. As lacunas não são internas à lei, mas demonstram suas relações com a realidade - a possibilidade de sua aplicação, como se no próprio direito existisse uma fratura importante entre o estabelecimento de uma norma e sua aplicação; lacuna esta que o estado de exceção, em situações extremas, preencheria, criando uma área em que a aplicação de determinada norma é suspensa, mas a lei que a criou continua a existir (AGAMBEN, 2007).

Deve-se compreender, também, o papel que o próprio conceito de necessidade exerce sobre o fundamento de um estado de exceção. Para isso, Agamben relembra o adágio latino de necessitas legem non habet, que significa "a necessidade não tem lei", podendo ser interpretado como "a necessidade não reconhece nenhuma lei" ou "a necessidade cria sua própria lei". Ambas as interpretações demonstram a ligação 
entre a teoria do estado de exceção e a de um estado de necessidade (status necessitatis), uma vez que o julgamento de condições de manutenção de um estado de necessidade torna legítimo um estado de exceção (AGAMBEN, 2007). Porém, é importante trazer algumas observações sobre o conceito de necessidade:

O conceito de necessidade é totalmente subjetivo, relativo ao objetivo que se quer atingir. (...) Um movimento revolucionário poderá declarar a necessidade de uma nova norma, abolindo os institutos vigentes contrários às novas exigências; mas é preciso estar de acordo quanto ao fato de que a ordem existente deve ser derrubada, em conformidade com essas novas exigências. Num caso como no outro (...) o recurso à necessidade implica uma avaliação moral ou política (ou, de toda forma, extrajurídica) pela qual se julga a ordem jurídica e se considera que é digna de ser conservada e fortalecida, ainda que à custa de sua eventual violação. Portanto, o princípio da necessidade é sempre, em todos os casos, um principio revolucionário. (BALLADORE-PALLIERI apud AGAMBEN, 2007, p. 46-47)

Desse modo, a necessidade se mostra completamente sujeita aos desejos que querem ser realizados, mas sempre sendo revolucionária no sentido de ser contra uma ordem vigente. Por isso, a necessidade precisa ser acompanhada de uma análise moral e política antes de ser consolidada juridicamente.

O estado de exceção em UNDERTALE ocorre em duas principais instâncias. A primeira delas diz respeito às medidas emergenciais que foram tomadas para assegurar o futuro da nação em detrimento de algumas liberdades individuais, fazendo com que a entidade máxima do poder - no caso Asgore - tomasse como sua obrigação um dever legislativo e julgasse como inferior o valor da vida dos humanos para priorizar a vida dos monstros, seus súditos. Ainda, é um exemplo em que a exceção tornou-se regra, já que a população do subterrâneo se encontrava nessa situação há algum tempo - noção que Agamben trouxe ao analisar as aplicações contemporâneas do estado de exceção. Inclusive, a própria discussão do conceito jurídico de necessidade pode ser aplicada neste contexto, visto que Asgore, o rei, julgou necessário que sua família não sentisse mais a dor de perder alguém e que o melhor método para liberar os monstros seria esperar que algum humano por acaso caísse no subterrâneo para destruí-lo e obter sua alma. Isso demonstra o caráter 
subjetivo da necessidade, já que alguns personagens do jogo (inclusive a própria Toriel, esposa de Asgore e rainha do subterrâneo) não aprovaram as medidas do rei. A segunda instância do estado de exceção ocorre no tratamento dos monstros com o protagonista. Além de o protagonista ser o único humano presente em meio aos monstros naquele momento da história de UNDERTALE, ele é o sétimo humano a cair naquele mundo, sendo a última alma humana necessária para poder quebrar a barreira daquele submundo e, desse modo, o último obstáculo que se coloca entre os monstros e o fim de seu sofrimento. Portanto, os monstros colocam o humano em uma zona de indiferenciação, mas dessa vez não explicitamente entre fato e direito, mas sim entre uma vida reconhecida e um inimigo a ser destruído, como se, de tal forma, os monstros também devessem escolher entre matar ou poupar a vida do protagonista, extrapolando a mecânica da tomada de decisão para os personagens dentro do próprio jogo.

\section{CONSIDERAÇÕES FINAIS}

O objetivo principal deste trabalho era perceber similaridades entre teorias da política e da comunicação nos videogames, com UNDERTALE como caso a ser analisado. A discussão se iniciou apresentando o caso de UNDERTALE, em que se pôde comentar sobre o conceito de individuação de Gilbert Simondon, apresentado por Gilles Deleuze. Simondon introduziu o conceito de pré-individual - um momento anterior à individuação no qual todas as possibilidades de singularidades são apresentadas para que, durante o próprio processo de individuação, o sujeito em questão se comunique com essas possibilidades e diferenças, assimilando-as e assim se tornando um ser "fasado", ou seja, dividido em fases de desenvolvimento de sua própria individualidade. Portanto, vimos que a presença do conceito de individuação em UNDERTALE se dá no processo de assimilar as possibilidades de rotas a serem seguidas, já que os jogadores precisam reconhecer as diferenças existentes nesse universo de possibilidades para escolherem o caminho com o qual mais se identificam, nas quais as personagens constantemente questionam o jogador se ele realmente acredita nas suas escolhas e no caminho que está seguindo. 
Contudo, esse processo de escolha é permeado por diversas situações de contradições e incongruências, que explicamos através da teoria do duplo vínculo de Gregory Bateson. Tais contradições, bem como ambiguidades e ambivalências, ocorrem frequentemente na comunicação, como vimos na situação com Toriel, apresentada logo nos primeiros momentos do jogo: um duplo vínculo estabelecido que deve perdurar durante todo o jogo. Bateson também encontra relações do duplo vínculo com os processos de aprendizagem, apresentando uma crítica ao modelo unidirecional de aprendizagem que é utilizado atualmente. Em UNDERTALE, o processo de aprendizagem se dá principalmente pela diferença encontrada na oferta de um modo de jogar pacifista, se opondo à maioria das lógicas encontradas em outros videogames, caracterizando assim o maior desafio para os jogadores pacifistas: romper com essas lógicas para poderem prosseguir com suas jornadas. Enfim, percebe-se que o duplo vínculo possui algum tipo de vício positivo em sua caracterização, visto que algumas pessoas se colocam em tais situações de forma voluntária; explicando, de certa forma, o porque de alguns jogadores optarem pela rota pacifista, uma jornada com o dobro de duração da genocida, mas apresentando mais explicações sobre a história do jogo além de outros conteúdos para os jogadores.

A discussão caminhou, então, para o conceito de estado de exceção de Giorgio Agamben, situação política na qual, para preservar o bem estar da nação, a entidade de liderança no momento assume poderes normalmente associados ao Judiciário, consequentemente prejudicando categorias de cidadãos que não se conformam ao novo modelo de estado. Ao discutir algumas aplicações históricas desse conceito, viuse que a construção dos próprios códigos legais pode possibilitar a instauração de estados de exceção, apresentando fraturas entre uma norma e sua aplicação, que o estado de exceção pode preencher. Igualmente, percebeu-se o papel da necessidade na consolidação desses estados, principalmente por sua natureza revolucionária, ainda que seja majoritariamente subjetiva. Entendeu-se, dessa forma, que a ambivalência entre as duas rotas principais de UNDERTALE (pacifista e genocida) é similar ao estado em que a monarquia do jogo se encontra: fato e direito não possuem limites definidos no mundo subterrâneo em estado de exceção após graves e 
sucessivos momentos de crise. Além disso, o estado de exceção foi extrapolado para fora dos limites de fato e direito, para englobar a indiferenciação entre uma vida reconhecida e um inimigo a ser destruído por um bem maior - situação na qual o protagonista se encontra frente aos monstros que aparecem em seu caminho. Ao enevoar os limites entre fato e direito, pôde-se também ver semelhanças entre 0 estado de exceção e a ambiguidade do duplo vínculo.

Por fim, discutiu-se o entendimento de Bateson sobre os vícios positivos, que podem ser a razão pela qual algumas pessoas voluntariamente se colocam em situações desconfortáveis de duplo vínculo e que devem ser considerados obstáculos a serem resolvidos. Neste momento do trabalho, indaga-se, no caso analisado, se esses vícios positivos ainda seriam considerados como tal, visto que os jogadores são recompensados pelos seus esforços, podendo aqui se associar a uma sensação de "dever cumprido" no lugar de um duplo vínculo desconfortável. Isso abre a discussão para a dúvida se determinados duplos vínculos assumidos voluntariamente podem ser, ao final, prazerosos ao invés de dolorosos. Conclui-se este trabalho, então, reconhecendo as similaridades do caso de UNDERTALE com as teorias analisadas.

\section{REFERÊNCIAS BIBLIOGRÁFICAS}

AGAMBEN, Giorgio. Estado de exceção. Tradução de Iraci D. Poleti. $2^{2}$ edição. São Paulo: Boitempo, 2007.

BATESON, Gregory. Una Unidad Sagrada: pasos ulteriores hasta una ecología de la mente. Barcelona: Gedisa, 2006.

Steps to an Ecology of Mind. $7^{a}$ edição. Nova York: Chandler Publishing Company, 1978.

DELEUZE, Gilles. Gilbert Simondon, o indivíduo e sua gênese físico-biológica. Caderno de Subjetividades. São Paulo, v. 11, 2003. 
3. Disponível em: <https://undertale.com/about/>. Acesso em: 26 jun. 2019. Tradução nossa.

Enviado: Novembro, 2019.

Aprovado: Novembro, 2019. 